\title{
A TRANSFERÊNCIA LINGUÍSTICA NA APRENDIZAGEM DE ESPANHOL COMO LÍNGUA ESTRANGEIRA POR APRENDIZES BRASILEIROS: UMA REVISÃO BIBLIOGRÁFICA
}

\author{
LANGUAGE TRANSFER IN THE LEARNING OF SPANISH AS A FOREIGN \\ LANGUAGE BY BRAZILIAN LEARNERS: A LITERATURE REVIEW
}

\author{
Raphaela Palombo Bica de Freitas ${ }^{1}$ \\ Bernardo Kolling Limberger ${ }^{2}$ \\ Isabella Mozzillo 3
}

\begin{abstract}
RESUMO: Este artigo tem como objetivo apresentar e discutir estudos sobre o fenômeno da transferência linguística na aprendizagem de espanhol como língua estrangeira por aprendizes brasileiros. Com esse fim, uma busca foi feita por estudos publicados entre 2010 e 2020 no Google Acadêmico, no portal de periódicos CAPES e na Biblioteca Digital Brasileira de Teses e Dissertações, resultando na seleção de 12 estudos que abordam a temática em questão. Esta revisão bibliográfica apresenta, brevemente, os objetivos, os participantes, os métodos e os resultados de cada estudo e discorre sobre o posicionamento dos autores no que diz respeito à transferência linguística, buscando mostrar as diferentes visões existentes sobre o mesmo fenômeno. Conclui-se que, mesmo não havendo um consenso entre os autores sobre o papel da transferência, sua existência, nos processos de ensino e aprendizagem de língua estrangeira, é inquestionável. Sendo assim, o estudo de tal fenômeno é essencial para o entendimento do papel da língua materna na aprendizagem de uma língua estrangeira.
\end{abstract}

PALAVRAS-CHAVE: Transferência linguística. Espanhol como língua estrangeira. Aprendizes brasileiros.

ABSTRACT: This article aims to present and discuss studies about the phenomenon language transfer in the learning of Spanish as a foreign language by Brazilian learners. For this purpose, a search was made for studies published between 2010 and 2020 in Google Schoolar, CAPES and Biblioteca Digital Brasileira de Teses e Dissertações databases which resulted in the selection of 12 studies that address the chosen theme. This literature review briefly presents the goals, participants, methodology and results of each study and discusses the positioning of the authors with regard to language transfer, seeking to show the different existing views about the same phenomenon. It has concluded that, even though there is no consensus among the authors on the role of transfer, its existence in the processes of teaching and learning a foreign language is unquestionable. Therefore, the study of this phenomenon is essential for understanding the role of the mother language in foreign language learning.

KEYWORDS: Language transfer. Spanish as a Foreign Language. Brazilian learners.

\section{Introdução}

A discussão sobre a influência da língua materna (LM) no ensino e na aprendizagem de línguas estrangeiras (LE) não é recente nos estudos da linguagem. Desde o final dos anos 1950, há uma tentativa de entender como se dá tal interação. Ao estudar uma nova língua, o estudante não a aprende do zero, tendo em vista que já possui um conhecimento complexo sobre o funcionamento de sua LM que estará presente e exercerá influências sobre a aprendizagem de uma LE. Como salienta Mozzillo: "A LM é um ponto de apoio porque, a partir de dados disponíveis sobre a LE, hipóteses sucessivas são elaboradas e testadas ao serem comparadas às

\footnotetext{
1 Mestranda em Letras (UFPEL), bolsista Capes. E-mail: raphaelabicadefreitas@hotmail.com. ORCID: https://orcid.org/0000-0003-1285-9798.

${ }^{2}$ Doutor em Letras/Linguística (PUCRS). Professor do Curso de Graduação em Letras - Português e Alemão e do Programa de Pós-Graduação em Letras (PPGL). Orcid: http://orcid.org/0000-0001-5504-2361. E-mail: limberger.bernardo@gmail.com

${ }^{3}$ Doutora em Letras/Linguística (PUCRS). Professora do Curso de Graduação em Letras - Português e Francês e do Programa de Pós-Graduação em Letras (PPGL). Orcid: http://orcid.org/0000-0001-8445-9174. E-mail: isabellamozzillo@gmail.com
} 
Volume 16 - Número 1 - jan/jul de 2021

produções nessa língua, o que permite o avanço no domínio linguístico"^45 (MOZZILLO, 2005, p. 71).

Diante do exposto, na presente revisão, serão mostrados e discutidos estudos que abordam o fenômeno da transferência linguística na aprendizagem da língua espanhola como língua estrangeira (ELE) por aprendizes brasileiros, buscando entender a influência que o português como LM exerce nesse processo. Dessa forma, podem-se compreender fatores que desempenham um papel importante na aprendizagem de espanhol por brasileiros.

Este artigo tem como objetivo principal apresentar e sistematizar alguns estudos sobre a temática escolhida, assim como suscitar, a partir das contribuições dos trabalhos selecionados, uma breve discussão sobre como a transferência é vista.

A presente revisão de literatura contém uma introdução, o referencial teórico e a metodologia seguidos pelos seus resultados. Logo, discutir-se-á, brevemente, o papel da transferência linguística na aprendizagem de ELE e, por último, serão tecidas as considerações finais.

\section{Referencial teórico}

Nesta seção, serão apresentados e discutidos os construtos teóricos que embasam os estudos selecionados para esta revisão bibliográfica. São eles: transferência linguística, análise contrastiva, análise de erros, interlíngua e fossilização.

\subsection{Transferência linguística}

O fenômeno da transferência linguística já recebeu inúmeras definições. Primeiramente, se tinha uma visão negativa a seu respeito, posto que ela seria a causa dos erros dos aprendizes de LE. Por isso, se utilizava o termo "interferência linguística" definido por Weinreich (1953) como desvios, frutos de fatores linguísticos e extralinguísticos, na fala do bilíngue em consequência da familiaridade que se tem com mais de uma língua.

$\mathrm{Na}$ área de aquisição de segunda língua, também surgiram termos como "transferência linguística positiva", "transferência linguística negativa" ou simplesmente transferência' com o fim de evitar a conotação negativa que o vocábulo "interferência" carregava. No mundo científico anglófono, o termo "influência translinguística" (crosslinguistic influence) proposto por Kellerman e Sharwood-Smith (1986) tem sido preferido para designar o mesmo fenômeno, no entanto, no Brasil, o termo ainda é pouco utilizado (FERREIRA, 2018).

Durão (2008) cita Lado (1957) ao distinguir transferência linguística positiva de transferência linguística negativa. A primeira consiste no uso produtivo da LM no desempenho da LE, devido às semelhanças existentes entre as duas línguas que causariam um efeito de facilitação em determinados contextos (por exemplo: traduzir a frase "A chave abriu a caixa" para o inglês corretamente devido à semelhança entre as estruturas das duas línguas). Já a segunda, consiste no uso não produtivo da LM no desempenho de uma LE em casos em que o funcionamento de ambas as línguas não coincide (por exemplo: utilizar "entre yo y tú" por influência do português quando o adequado seria "entre tú y yo").

De acordo com Ottonello (2004), a transferência pode ser vista como uma estratégia da qual o aprendiz faz uso para suprir lacunas de conhecimento na língua-alvo. Trata-se, portanto,

\footnotetext{
${ }^{4}$ Texto original: "La LM es un punto de apoyo porque, a partir de datos disponibles sobre la LE, se elaboran las hipótesis sucesivas que se testan al compararse con las producciones en esa lengua, lo que permite el avance en el dominio lingüístico."

${ }^{5}$ Todas as traduções de termos e citações originalmente escritas em inglês ou espanhol são de responsabilidade dos autores.
} 
de um fenômeno natural e inevitável no processo de aprendizagem de segunda língua (L2) que afeta tanto sua produção como sua recepção (SALCEDO, 2017).

No caso da aprendizagem de espanhol por brasileiros, a proximidade entre as duas línguas pode ser considerada como benéfica no início da aprendizagem, mas dificultadora em estágios avançados (VILLALBA, 2002). Em consonância, Salcedo (2017) afirma que, por um lado, a proximidade facilita a compreensão e expressão na L2, mas, por outro, dificulta a compreensão e expressão adequada na L2. Como será visto a seguir, a visão que se tem sobre a transferência sofreu modificações entre o modelo da Análise Contrastiva e o da Análise de Erros.

\subsection{A Análise Contrastiva e a Análise de Erros}

A Análise Contrastiva (AC) é uma corrente dentro da Linguística Contrastiva que compara as línguas para determinar os erros potenciais do estudante e estabelecer o que precisa ou não ser aprendido no contexto de ensino de uma L2 (GASS; SELINKER, 2008). De acordo com os autores, para a AC, aprender uma nova língua consiste na aprendizagem de novos hábitos e, nesse processo, a dificuldade e a facilidade no estudo de uma L2 é determinada, respectivamente, pelas diferenças e semelhanças desta com a LM. Sendo assim, no processo de aprendizagem o foco deve ser nas diferenças entre as línguas uma vez que as semelhanças não envolveriam nenhuma aprendizagem nova. Além do mais, de acordo com a perspectiva da AC, a LM é a principal fonte de erros tanto na produção quanto na recepção da L2 (GASS; SELINKER, 2008).

No entanto, com o tempo, a $\mathrm{AC}$ foi perdendo força, já que não explicava muitos dos erros no processo de aprendizagem de uma LE, que, muitas vezes, não eram causados pela influência da LM. Um estudo que contestou essa teoria foi o de Oller e Ziahosseiny (1970), ao comprovar que houve uma vantagem, ao aprender a ortografia do inglês como L2, dos estudantes cuja língua nativa utiliza um alfabeto não românico em comparação aos estudantes cuja língua nativa faz uso de um alfabeto românico. Contrariou-se, assim, os pressupostos da AC, já que aprendizes que possuíam uma LM mais distante da LE tiveram uma maior facilidade: "Aparentemente, o conhecimento de um sistema ortográfico românico torna mais difícil e não menos difícil a aquisição de outro sistema ortográfico românico " "OLLER; ZIAHOSSEINY, 1970, p. 188, grifo dos autores).

Surge, então, a Análise de Erros (AE), uma corrente que valoriza o erro como constituinte importante na aprendizagem de uma LE. Nessa concepção, o erro não é um mero produto de uma aprendizagem imperfeita, mas, sim, mostra a tentativa do aprendiz de entender esse novo sistema (LE), na busca de sua regularidade (GASS; SELINKER, 2008). Seguindo essa linha de raciocínio, Corder (1967) afirma que os erros são significantes de três maneiras: para o professor, pois mostram quanto o estudante progrediu e o que ainda falta para ser aprendido, para o pesquisador, pois mostram como a língua é aprendida ou adquirida e, para o próprio estudante, já que os erros são um dispositivo usado para testar hipóteses sobre a língua.

Além disso, a $\mathrm{AE}$ reconhece que a interferência não é a única fonte dos erros, que também podem ser causados por: interferência intralingual, interferência de outras LE, interferências de outros dialetos da LM, fatores sociolinguísticos, idade, fatores fisiopsicológicos, modalidade de exposição à LE e metodologia de ensino (MAGRO, 1979).

\subsection{Interlíngua e fossilização}

\footnotetext{
${ }^{6}$ Os termos "língua estrangeira" e "segunda língua" serão utilizados sem distinção assim como "L1" e "LM".

${ }^{7}$ Texto original: "Apparently, knowledge of one Roman writing system makes it more difficult, not less, to acquire another Roman spelling system".
} 
Volume 16 - Número 1 - jan/jul de 2021

Como foi mencionado anteriormente, com o surgimento da $\mathrm{AE}$, que considera o erro importante, o estudante de LE passa a ser visto como ativo no processo de aprendizagem. Assim, o aprendiz faria uso de variadas estratégias com o propósito de entender melhor o funcionamento do sistema da nova língua. Segundo Selinker (1972), o aprendiz tem um sistema linguístico próprio, diferente do de um falante nativo. Esse sistema, denominado de interlíngua (IL), consiste numa tentativa de produção das normas da língua-alvo.

Fernández López (1995) compactua com o conceito de Selinker e trata a IL como um sistema de diferentes estágios pelos quais o aprendiz passa no percurso de apropriação da língua-alvo. Nesse processo, é natural a produção de estruturas corretas e erradas. Os erros do aprendiz refletem diferentes estratégias de aprendizagem que mudariam de acordo com o estágio no qual o aprendiz se encontraria. Além disso, conforme afirma Mozzillo (2005), a IL é, ao mesmo tempo, um processo de aproximação da língua-alvo e o produto do contato entre as línguas no ambiente de sala de aula.

Atrelado ao conceito de IL há também o fenômeno de fossilização, que ocorre quando estruturas linguísticas que não correspondem às da língua-alvo são produzidas regularmente por aprendizes de L2 e se fixam na sua IL (DURÃO, 2000). Para Selinker (1972), a fossilização ocorre quando o aprendiz falante de determinada LM mantém determinados itens linguísticos, regras e subsistemas na IL de sua língua-alvo independentemente da quantidade de instrução recebida.

\section{Método}

Para a presente revisão bibliográfica, foram feitas buscas no portal de periódicos da CAPES, na Biblioteca Digital Brasileira de Teses e Dissertações (BDTD) e no Google Acadêmico por trabalhos revisados por pares publicados entre os anos de 2010 a 2020, que tratassem da transferência linguística na aprendizagem de ELE por brasileiros. Esse período de 10 anos foi escolhido para abranger os trabalhos mais recentes sobre a temática.

No portal de periódicos da CAPES e na BDTD, foram utilizadas as palavras-chave "transferência" e "espanhol", já no Google Acadêmico, optou-se pelos termos "transferência linguística"8 e "espanhol".

Após feita a busca, foram vistos todos os títulos dos trabalhos encontrados e somente aqueles que tratavam da temática tiveram seus resumos lidos. Foram excluídos trabalhos publicados antes de 2010, trabalhos que não abordavam a transferência linguística especificamente do espanhol para o português, trabalhos nos quais a língua espanhola era a LM ou o português era a LE, estudos sobre o fenômeno envolvendo outras línguas (como o inglês) e estudos que analisavam a aquisição do espanhol por brasileiros, mas que não focavam no fenômeno da transferência. Finalmente, foram selecionados 12 estudos para a presente revisão bibliográfica.

\section{Resultados}

A procura no portal de periódicos da CAPES gerou 328 resultados, no Google Acadêmicos, 512 resultados e, na BDTD, 23 resultados. Os 12 estudos selecionados serão apresentados considerando a ordem cronológica de publicação. Para fins de esclarecimento,

\footnotetext{
${ }^{8}$ Usou-se especificamente o termo "transferência linguística" para evitar a confusão com o termo "transferência", advindo do campo da Psicologia.
} 
serão mostrados, na tabela a seguir, os objetivos, participantes, métodos (no caso de estudos empíricos) e resultados dos estudos escolhidos ${ }^{9}$ :

Quadro 1- Nome dos autores, objetivos, métodos, participantes e resultados dos artigos sobre transferência linguística.

\begin{tabular}{|c|c|c|c|c|}
\hline Estudo & Objetivo & $\begin{array}{l}\text { Métodos } \\
\end{array}$ & Participantes & Resultados \\
\hline $\begin{array}{l}\text { Andrade } \\
(2010)\end{array}$ & $\begin{array}{l}\text { Levantar, descrever e } \\
\text { analisar os desvios } \\
\text { léxico-semânticos na IL } \\
\text { oral }\end{array}$ & Entrevistas gravadas & $\begin{array}{l}24 \text { alunos do curso de } \\
\text { Letras Estrangeiras } \\
\text { Modernas (inglês e } \\
\text { espanhol) e de Letras } \\
\text { Hispano-portuguesas }\end{array}$ & 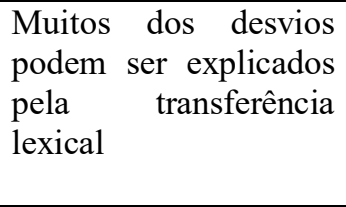 \\
\hline $\begin{array}{l}\text { Dias } \quad \text { e } \\
\text { Morosov } \\
\text { (2013) }\end{array}$ & $\begin{array}{l}\text { Discutir sobre o porquê } \\
\text { de os alunos brasileiros } \\
\text { apresentarem } \\
\text { dificuldades com } \quad \text { o } \\
\text { verbo gustar }\end{array}$ & Não se aplica & Não se aplica & $\begin{array}{l}\text { A dificuldade pode ser } \\
\text { explicada devido à } \\
\text { tendência de os } \\
\text { aprendizes de transferir } \\
\text { a estrutura semântica } \\
\text { do verbo gostar do } \\
\text { português para } \\
\text { espanhol }\end{array}$ \\
\hline $\begin{array}{l}\text { Gomes e } \\
\text { Carvalho } \\
\text { (2013) }\end{array}$ & $\begin{array}{lr}\text { Investigar } & \text { a } \\
\text { interferência } & \text { do } \\
\text { português como LM no } \\
\text { processo } & \text { de } \\
\text { aprendizagem } & \text { de } \\
\text { espanhol como LE } & \text { no } \\
\text { uso do léxico } & \\
\end{array}$ & $\begin{array}{l}\text { Exercícios } \\
\text { envolvendo produção } \\
\text { de texto e análise de } \\
\text { frases com } \\
\text { heterossemânticos }\end{array}$ & $\begin{array}{l}5 \text { alunos do } 6^{\circ} \text { período de } \\
\text { Letras-Espanhol da } \\
\text { Universidade Estadual } \\
\text { do Rio Grande do Norte }\end{array}$ & $\begin{array}{l}\text { Houve interferência no } \\
\text { léxico }\end{array}$ \\
\hline $\begin{array}{l}\text { Moraes e } \\
\text { Lima (2015) }\end{array}$ & $\begin{array}{l}\text { Analisar a transferência } \\
\text { no uso do presente do } \\
\text { subjuntivo com a } \\
\text { conjunção subordinada } \\
\text { adverbial cuando }\end{array}$ & $\begin{array}{l}\text { Aplicação } r \text { de } \\
\text { atividades orais e } \\
\text { escritas e entrevistas } \\
\text { narrativas }\end{array}$ & $\begin{array}{l}12 \text { alunos estudantes do } \\
6^{\circ} \text { semestre do curso de } \\
\text { Letras-Espanhol de uma } \\
\text { universidade privada no } \\
\text { interior do Rio Grande } \\
\text { do Sul }\end{array}$ & $\begin{array}{l}\text { Ocorreu transferência } \\
\text { na produção oral e } \\
\text { escrita do presente do } \\
\text { subjuntivo } \quad \text { em } \\
\text { espanhol }\end{array}$ \\
\hline $\begin{array}{l}\text { Dutra } \\
(2015)\end{array}$ & $\begin{array}{l}\text { Examinar os efeitos e a } \\
\text { durabilidade do } \\
\text { tratamento instrucional } \\
\text { na } \\
\text { aquisição/aprendizagem } \\
\text { dos clíticos de terceira } \\
\text { pessoa do Espanhol }\end{array}$ & $\begin{array}{l}\text { Julgamento de } \\
\text { gramaticalidade, } \\
\text { teste de imitação oral, } \\
\text { teste de descrição de } \\
\text { sequência de imagens } \\
\text { e teste de narrativa } \\
\text { oral }\end{array}$ & $\begin{array}{l}10 \text { estudantes do curso } \\
\text { de Letras: } 6 \text { do } 3^{\circ} \\
\text { semestre, } 2 \text { do } 5^{\circ} \text { e } 2 \text { do } \\
7^{\circ} \text {. }\end{array}$ & $\begin{array}{lr}\text { O tratamento } & \\
\text { instrucional ocasionou } \\
\text { a redução } \\
\text { transferência } \\
\text { linguística } \\
\begin{array}{lr}\text { português para } \\
\text { espanhol do }\end{array} \\
\end{array}$ \\
\hline $\begin{array}{l}\text { Salcedo } \\
\text { (2017) }\end{array}$ & $\begin{array}{l}\text { Observar os casos de } \\
\text { transferência negativa } \\
\text { do verbo suporte ficar }\end{array}$ & $\begin{array}{l}\text { Produções escritas de } \\
\text { contos de fadas e } \\
\text { histórias fantásticas }\end{array}$ & 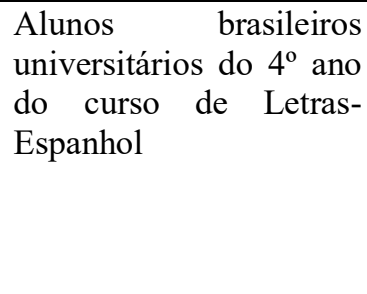 & $\begin{array}{l}\text { Os alunos transferiram } \\
\text { o verbo ficar do } \\
\text { português aplicando-o } \\
\text { em contextos em que } \\
\text { outros verbos do } \\
\text { espanhol se } \\
\text { enquadrariam melhor }\end{array}$ \\
\hline $\begin{array}{l}\text { Gomes } \\
(2017)\end{array}$ & $\begin{array}{l}\text { Averiguar a existência } \\
\text { de interferência e } \\
\text { transferência de valores } \\
\text { paramétricos da L1 } \\
\text { (português) na produção } \\
\text { escrita de aprendizes de } \\
\text { espanhol como L2 em } \\
\text { subordinadas finais }\end{array}$ & $\begin{array}{ll}\text { Entrevistas } & \\
\text { conversacionais, } & \\
\text { questionários } & \text { de } \\
\text { identificação } & \text { e } \\
\text { produção textual em } & \text { em } \\
\text { língua espanhola } & \end{array}$ & $\begin{array}{l}3 \text { professores } \\
\text { aprendizes de Espanhol } \\
\text { do Centro Interescolar de } \\
\text { Línguas de Brazlândia } \\
\text { (CILB), escola pública } \\
\text { do Distrito Federal }\end{array}$ & $\begin{array}{l}\text { Há interferência e } \\
\text { transferência de } \\
\text { valores paramétricos } \\
\text { da L1 no processo da } \\
\text { aquisição de espanhol } \\
\text { como L2 }\end{array}$ \\
\hline
\end{tabular}

\footnotetext{
${ }^{9}$ Os termos "transferência" e "interferência" foram mantidos de acordo com o uso feito pelos autores de cada artigo.
} 
Volume 16 - Número 1 - jan/jul de 2021

\begin{tabular}{|c|c|c|c|c|}
\hline $\begin{array}{l}\text { Corrêa } \\
\text { Araujo } \\
(2018)\end{array}$ & $\begin{array}{l}\text { Verificar se o estudante } \\
\text { de ELE apropria-se das } \\
\text { características r do } \\
\text { Pretéritor Perfeito } \\
\text { Composto do português } \\
\text { ao usar o espanhol }\end{array}$ & $\begin{array}{l}\text { Análise de áudios de } \\
\text { diferentes gêneros } \\
\text { discursivos: } \\
\text { apresentação, debate } \\
\text { e diálogo }\end{array}$ & 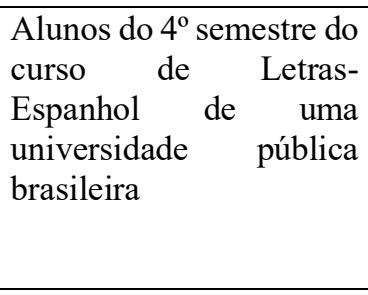 & $\begin{array}{l}\text { Não há interferência } \\
\text { semântica } \\
\text { morfológica } \\
\text { significativa da LM no } \\
\text { uso do Pretérito } \\
\text { Perfeito Composto do } \\
\text { espanhol. }\end{array}$ \\
\hline $\begin{array}{l}\text { Poza e Melo } \\
\text { (2018) }\end{array}$ & $\begin{array}{l}\text { Analisar o fenômeno da } \\
\text { interlíngua nos } \\
\text { marcadores discursivos } \\
\text { em língua espanhola }\end{array}$ & $\begin{array}{l}\text { Gravações em sala de } \\
\text { aula }\end{array}$ & $\begin{array}{l}\text { Professores e alunos de } \\
\text { espanhol avançado }\end{array}$ & $\begin{array}{lr}\text { Na produção de alunos } \\
\text { e professores, } & 43,47 \% \\
\text { dos } & \text { marcadores } \\
\text { discursivos } & \text { foram } \\
\text { transferidos } & \text { do } \\
\text { português para } & \text { } \\
\text { espanhol, } & 43,47 \% \\
\text { foram mal traduzidos e } \\
13,04 \% \text { apresentavam } \\
\text { problemas } \\
\text { transferência. }\end{array}$ \\
\hline $\begin{array}{l}\text { França } \\
(2018)\end{array}$ & $\begin{array}{lr}\text { Apresentar } & \text { algumas } \\
\text { dificuldades } & \text { dos } \\
\text { aprendizes brasileiros } \\
\text { em relação à escrita em } \\
\text { língua espanhola }\end{array}$ & Não se aplica & Não se aplica & $\begin{array}{l}\text { A interferência da LM } \\
\text { é um dos fatores que } \\
\text { dificulta o processo de } \\
\text { escrita dos aprendizes. }\end{array}$ \\
\hline $\begin{array}{l}\text { Moraes, } \\
\text { Dutra } \\
\text { Simioni } \\
(2018)\end{array}$ & $\begin{array}{l}\text { Verificar os efeitos e a } \\
\text { durabilidade da } \\
\text { intervenção instrucional } \\
\text { na redução da não } \\
\text { aplicação do presente do } \\
\text { subjuntivo do espanhol } \\
\text { em orações temporais } \\
\text { com cuando }\end{array}$ & $\begin{array}{l}\text { Tarefas de produção } \\
\text { oral e escrita }\end{array}$ & $\begin{array}{l}12 \text { estudantes do curso } \\
\text { de Letras-Português, } \\
\text { Espanhol e respectivas } \\
\text { Literaturas de uma } \\
\text { universidade privada do } \\
\text { Rio Grande do Sul }\end{array}$ & $\begin{array}{l}\text { Houve maior aplicação } \\
\text { do presente r do } \\
\text { subjuntivo após a } \\
\text { intervenção }\end{array}$ \\
\hline $\begin{array}{l}\text { Machado } \\
\text { (2019) }\end{array}$ & $\begin{array}{l}\text { Comparar a produção de } \\
\text { vogais de dois grupos de } \\
\text { estudantes } \\
\text { averiguar se há uma } \\
\text { maior influência da LM } \\
\text { na produção vocálica do } \\
\text { grupo de estudantes que } \\
\text { residem longe da } \\
\text { fronteira }\end{array}$ & $\begin{array}{l}\text { Testes de análise } \\
\text { acústica envolvendo } \\
\text { a produção de } \\
\text { palavras dissílabas de } \\
\text { alta frequência }\end{array}$ & $\begin{array}{l}8 \text { estudantes de cursos de } \\
\text { Licenciatura em Letras- } \\
\text { Português e Espanhol } \\
\text { sendo quatro de uma } \\
\text { universidade perto da } \\
\text { fronteira com o Uruguai } \\
\text { e quatro de uma } \\
\text { universidade } \\
\text { distante }\end{array}$ & $\begin{array}{l}\text { O fato de os estudantes } \\
\text { morarem perto da } \\
\text { fronteira não é um fator } \\
\text { para a diminuição da } \\
\text { transferência } \\
\text { linguística que pode ser } \\
\text { ocasionada pela } \\
\text { memória articulatória } \\
\text { dos aprendizes }\end{array}$ \\
\hline
\end{tabular}

Fonte: Os autores.

\section{Discussão}

A maior parte dos trabalhos está escrita em língua portuguesa, sendo somente um escrito em língua espanhola. Ademais, a maioria dos estudos é empírica e conta com a participação de alunos do curso de Letras-Espanhol. Embora apresentem diferentes métodos, prevalece a coleta da produção oral dos participantes. A seguir, serão discutidos os estudos de acordo com seu foco.

\subsection{Estudos que envolvem a transferência no uso de estruturas verbais}

A maioria dos estudos desta revisão tem como temática a transferência no uso de estruturas verbais. São eles: Dias e Morosov (2013), Moraes e Lima (2015), Salcedo (2017), Gomes (2017), Corrêa e Araujo (2018) e Moraes, Dutra e Simioni (2018).

O estudo de Corrêa e Araujo (2018) trata da transferência do pretérito perfecto compuesto (PPC). Os autores realizam uma análise contrastiva entre o PPC do português e o do 
espanhol. Para descobrir a existência de transferência morfológica e semântica do PPC, usaram como base um corpus oral de 44 áudios de alunos do $4^{\circ}$ semestre do curso de Letras-Espanhol e analisaram 28 ocorrências do PPC do espanhol. Dessas ocorrências, 71\% estavam de acordo com a norma padrão em que o PPC tem valor de antepresente. Os autores concluem que o aprendiz de nível intermediário não sofre tanta interferência semântica e morfológica da LM no que diz respeito ao uso do PPC, uma vez que a grande maioria o utilizou de acordo com a norma, no entanto foram encontrados, embora em menor quantidade, processos de generalização morfológica e semântica em alguns usos do tempo verbal.

Outros dois estudos que tratam da transferência no uso de estruturas verbais são os de Moraes e Lima (2015) e o de Moraes, Dutra e Simioni (2018), que abordam a transferência no uso do presente do subjuntivo do espanhol em orações temporais com cuando por universitários brasileiros. No primeiro estudo, após constatar a ocorrência de transferência na oralidade e na escrita de 12 alunos de Letras em atividades de preenchimento de lacunas, múltipla escolha, descrição de imagem e criação de história, a pesquisadora e a professora titular da turma planejaram e aplicaram duas aulas específicas sobre o uso do presente do subjuntivo com a conjunção cuando. Posteriormente, os alunos realizaram entrevistas narrativas. As autoras do estudo verificaram que, após as aulas específicas sobre o presente do subjuntivo do espanhol, os alunos sentiram-se mais seguros ao usá-lo e admitiram não saber anteriormente sobre o seu funcionamento. Também, os estudantes manifestaram a importância de ter mais aulas voltadas para a gramática e, ainda, apresentaram dúvidas quanto à facilidade (ou não) de aprender ELE devido a sua semelhança com a língua portuguesa.

Moraes, Dutra e Simioni (2018) também notaram, em tarefas de produção oral e escrita de 12 estudantes do curso de Letras-Espanhol e Português, a ocorrência de inadequações no uso do presente do subjuntivo, como empréstimos do português em orações como "Cuando estiver en Barcelona", transferências linguísticas com o uso do futuro do subjuntivo do português em casos como "Cuando salirmos del cine" (o infinitivo flexionado não existe no espanhol, que exige o uso do presente do subjuntivo nessa construção) e o emprego de formas alternativas como o verbo no presente do indicativo ou no pretérito indefinido no lugar do presente do subjuntivo. Após a instrução com foco na forma, que consistia em aulas expositivas sobre os modos indicativo e subjuntivo e explicações sobre as diferenças entre o presente do subjuntivo do espanhol e o futuro do subjuntivo do português, os alunos realizaram novamente tarefas de produção e escrita cujos resultados apresentaram uma redução no uso de formas alternativas para o presente do subjuntivo no espanhol, corroborando com a hipótese dos autores de que a instrução com foco na forma pode ser muito vantajosa para a diminuição da transferência linguística.

Os estudos de Salcedo (2017) e o de Gomes (2017) também apontam, empiricamente, para a presença de transferência do português para o espanhol de estruturas verbais. Gomes (2017), ao analisar a interferência do infinitivo flexionado na escrita de subordinadas finais, faz uma distinção entre a forma dessas orações na língua portuguesa e na espanhola. No espanhol, o infinitivo não carrega marcas de pessoalidade, não permitindo, assim, a existência do infinitivo flexionado. A partir das produções de três professores, a autora constata que, em casos de orações finais com sujeitos correferenciais (com o mesmo sujeito), todos os participantes demonstraram ter fixado o parâmetro do espanhol de não flexão do infinitivo. No entanto, em construções com sujeitos não correferenciais (com sujeitos diferentes), foram encontradas interferências do parâmetro da flexão do infinitivo do português como no caso de "Poner la grabación/ para ellos señalaren en el dibujo los consejos que oigan”. A autora chama a atenção para o fato de que os mesmos sujeitos que produziram construções com interferência também produziram diversas vezes o infinitivo de forma correta no espanhol e conclui que há interferência e transferência de valores paramétricos da L1 no processo da aquisição de espanhol como L2. 
Volume 16 - Número 1 - jan/jul de 2021

Por sua vez, o estudo de Salcedo (2017) analisa a transferência negativa do verbo ficar como equivalente ao verbo quedar do espanhol em 50 produções escritas de contos de fadas e histórias fantásticas de alunos brasileiros universitários do $4^{\circ}$ ano do curso de Letras-Espanhol. A autora ressalta a tendência de os estudantes transferirem a estrutura do português para o espanhol ao usarem o verbo ficar em contextos em que outros verbos se enquadrariam melhor. Consequentemente, Salcedo (2017) aponta para a vantagem de um estudo contrastivo para diferenciar a LE da LM e defende que o espanhol falado por brasileiros deve ser reconhecido como um sistema linguístico independente, pois possui características próprias que o diferenciam da língua espanhola de um falante nativo.

Finalmente, o estudo de Dias e Morosov (2013) é o único não empírico que envolve a transferência no uso de estruturas verbais. As autoras, ao se questionarem sobre a dificuldade dos brasileiros com o uso do verbo gustar, realizam uma breve análise do verbo levando em consideração a teoria dos papéis temáticos. O gustar e o gostar compartilham a característica de serem um predicado de dois argumentos (experienciador e tema), porém a categoria sintática dos argumentos muda de uma língua para a outra. Para exemplificar, as autoras utilizam as sentenças "Maria gosta do João" e seu equivalente em espanhol "A María le gusta Juan". Em ambas as frases, "Maria/María" cumpre o papel temático de experienciador e "João/Juan", o de tema. Porém, as palavras "Maria" e "João" exercem, em português, a função sintática de sujeito e objeto preposicionado, respectivamente, quando, em espanhol, a situação se inverte, sendo "María/le" o objeto indireto e Juan o sujeito. Dias e Morosov (2013) concluem que o emprego do verbo gustar com a estrutura sintática da língua portuguesa ocorre devido a uma transferência da estrutura semântica do verbo gostar para a representação superficial do espanhol.

\subsection{Estudos que envolvem a transferência no uso do léxico}

A transferência no uso do léxico é abordada por quatro estudos: Andrade (2010), Gomes e Carvalho (2013), Dutra (2015) e Poza e Melo (2018). Os estudos possuem metodologias diferentes, mas a maioria aborda a produção oral de estudantes de Letras-Espanhol.

O estudo de Gomes e Carvalho (2013) investiga a interferência do português no uso do léxico por meio de duas atividades aplicadas para cinco alunos do $6^{\circ}$ período de LetrasEspanhol. A primeira atividade consistia na produção de um texto e a segunda consistia na contextualização de 10 heterossemânticos do espanhol. As autoras notaram, na produção dos alunos, múltiplos casos de transferência negativa do léxico do português para o espanhol em casos como "estudiei", "jugava", "acostumando", assim como o desconhecimento dos falsos cognatos a partir de frases como "la salada está ensalada" e "¿estás zurdo?". As autoras sugerem que, com o fim de evitar a interferência, os estudantes devem ter claras as diferenças dos sistemas da LM e da LE:

É fundamental considerarmos que cada língua possui seu próprio sistema, e o aprendiz necessita ter consciência das diferenças e falsas semelhanças existentes entre essas línguas no processo de aprendizagem, para evitar as estratégias de transferência, que possam favorecer a interferência, erros que afetem a comunicação e venham ser eventualmente fossilizados. (GOMES; CARVALHO, 2013, p. 90).

Da mesma forma, Poza e Melo (2018) analisaram que os equívocos causados pela transferência podem afetar a comunicação. Os autores analisaram a interferência linguística no uso dos marcadores discursivos nas produções de alunos e de professores de uma universidade e observaram que ambos apresentaram interferências no uso de marcadores discursivos que podem comprometer o significado. Ocorreram, nas produções, marcadores transferidos do português diretamente para o espanhol como "mas", "na verdade" "assim", "né", e marcadores 
Volume 16 - Número 1 - jan/jul de 2021

discursivos mal traduzidos como “¿cierto?”, “mismo que”, “buen”, “iperciben?”, entre outros. Os autores concluem que são necessários mais estudos que tratem dos marcadores discursivos, elementos importantes no momento da interação.

Por outro lado, Dutra (2015) defende, assim como Moraes e Lima (2015), citados na subseção anterior, a importância da instrução com foco na forma tendo em vista a similaridade entre português e espanhol. Ao realizar uma intervenção pedagógica com alunos de diferentes semestres das Letras, na qual se abordou o contraste entre o funcionamento das formas clíticas de terceira pessoa do espanhol em relação ao português, percebeu-se, posteriormente, um maior uso das formas-alvo, indicando que os limites linguísticos entre o português e o espanhol ficaram mais claros.

Finalmente, o estudo de Andrade (2010) analisa, a partir de entrevistas gravadas, os desvios léxico-semânticos (incluindo falsos cognatos, colocações e expressões idiomáticas) na IL de 24 alunos de Letras e afirma que a estratégia de transferência de itens lexicais é o recurso mais usado pelos aprendizes para suprir necessidades léxicas na modalidade escrita e oral do espanhol.

\subsection{Estudos que envolvem a transferência na produção de sons e na escrita}

Finalmente, incluímos aqui estudos com temáticas diferentes que não se encaixam nas categorias anteriores como o de França (2018) e o de Machado (2019).

França (2018) tece considerações mais gerais sobre as dificuldades na aprendizagem da escrita do espanhol no Brasil a partir da pesquisa de Rabasa (2011), que investigou a interlíngua de alunos e professores do $2^{\circ}$ semestre do curso de Letras-Espanhol por meio da AC e da AE. França (2018), ao analisar os dados, constata que ocorreu a transferência da estrutura do português para o novo sistema linguístico em casos como "(...) hacendo con que sean mirados los dos lados de la moneda (...)", assim como alguns empréstimos literais em que a grafia foi conservada como em "Acredito que hoy en día (...)". A autora conclui que, na IL dos participantes, ocorre uma mistura de elementos do espanhol e do português, assim como outros de criação própria, e considera a existência de fatores que dificultam o processo de escrita, como a motivação do aluno e a própria interferência da LM.

Já o estudo de Machado (2019), ao comparar a produção vocálica de 8 estudantes de Letras, sendo 4 de uma universidade perto da fronteira com o Uruguai e 4 de uma universidade distante da fronteira, verificou que não houve diferenças significativas entre a produção desses alunos. Desse modo, concluiu-se que houve transferência linguística mesmo na produção dos estudantes que residiam próximos à fronteira.

\section{O papel da transferência linguística no ensino e na aprendizagem de ELE}

Os autores dos artigos selecionados para a presente revisão manifestam diferentes posicionamentos no que diz respeito ao papel que exerce a transferência linguística na aprendizagem de ELE. A partir da leitura dos trabalhos, foram elaboradas categorias nas quais os trabalhos se encaixariam de acordo com o seu posicionamento em relação ao fenômeno da transferência:

a) No processo de aprendizagem, é necessário evitar as estratégias de transferência que possam favorecer a interferência.

Tal afirmação é feita por Gomes e Carvalho (2013), que chamam a atenção para o fato de que a facilidade para aprender espanhol é um mito, já que, ao mesmo tempo que a semelhança entre as duas línguas pode facilitar a aprendizagem do léxico, as interferências podem afetar a comunicação. Segundo as autoras, a interferência é um "problema real" (2013, p. 81), que deve 
se beneficiar das abordagens da AC e da AE. Em consonância, segundo Dutra (2015), a semelhança entre o português e o espanhol não parece facilitar a aprendizagem da LE, posto que as semelhanças e as falsas semelhanças entre as línguas dificultariam a determinação de limites linguísticos.

Gomes e Carvalho (2013) também afirmam que a transferência não é favorável em estágios mais avançados, pois "pode contribuir para que os aprendizes permaneçam numa IL, o que não é um aspecto favorável no que concerne à aprendizagem de LE" (p. 84).

Por sua vez, Salcedo (2017), França (2018) e Moraes e Lima (2015), Moraes, Dutra e Simioni (2018) não apontam para o fato de que a interlíngua pode ser superada, mas também colocam a interferência da LM como fator de dificuldade em níveis mais avançados de aprendizagem da LE. No entanto, Salcedo (2017) e França (2018) reforçam que há também outras causas dos erros dos aprendizes, como a hipercorreção e a automatização de regras incorretas.

Embora alguns autores chamem a atenção para o aspecto negativo da transferência, muitos ressaltam a sua importância como recurso de aprendizagem de LE, como mostra a categoria a seguir.

b) A transferência linguística pode ser uma estratégia de comunicação.

De acordo com Moraes, Dutra e Simioni (2018), a transferência é utilizada para suprir lacunas de conhecimento linguístico da língua-alvo e é motivada pela proximidade tipológica entre as línguas que causa a ausência de percepção dos limites de proximidade e de distância entre as línguas envolvidas. Em concordância, Andrade (2010), Gomes e Carvalho (2013), Salcedo (2017), França (2018), Corrêa e Araujo (2018), Poza e Melo (2018), Moraes, Dutra e Simioni (2018) e Machado (2019) consideram a transferência linguística como estratégia de comunicação e desenvolvimento na língua-alvo:

Nesse sentido, a interferência da língua materna na produção em língua estrangeira não deve ser entendida como um erro, mas como uma importante estratégia de aprendizagem e de comunicação, que se torna menos recorrente à medida que o aprendiz avança na experiência e conhecimento sobre o funcionamento da língua estrangeira. (CORRÊA; ARAUJO, 2018, p. 151).

Nessa mesma linha de raciocínio, Gomes e Carvalho (2013) citam Baralo (1999), que afirma que a transferência é uma estratégia para compensar a carência de conhecimento na língua-alvo. Ademais, para que o aprendiz alcance seus objetivos comunicacionais e interacionais (POZA; MELO, 2018), este pode ser beneficiar da transferência como um recurso (SALCEDO, 2017) que "atua como um andaime cognitivo na construção do conhecimento acerca da L2” (ZIMMER, 2003, p. 62 apud MACHADO, 2019, p. 30).

De forma semelhante, França (2018) salienta que os erros provenientes da influência da LM do aprendiz devem ser valorizados, pois são inevitáveis e fazem parte do processo de aprendizagem:

c) A transferência da LM sempre estará presente na aprendizagem de uma LE.

Alguns autores conceituam a transferência como fenômeno natural e pertencente ao processo de aprendizagem de LE. Corrêa e Araujo (2018), por exemplo, afirmam que a transferência é um fenômeno característico da IL. Também Salcedo (2017) corrobora essa visão ao afirmar que

a transferência é um fenômeno natural que facilita que o estudante da L2 transfira o conhecimento linguístico da sua língua materna para a língua-alvo durante a aprendizagem dessa L2 [...] a "transferência linguística" não apenas parece inevitável, mas também é imprescindível no processo de aquisição de uma L2 ${ }^{10}$. (SALCEDO, 2017, p. 132, grifo da autora).

10 Texto original: "la transferencia es un fenómeno natural que facilita al estudiante de L2 transferir el conocimiento lingüístico de su lengua materna al de la lengua meta durante el proceso de aprendizaje de esa L2 
Volume 16 - Número 1 - jan/jul de 2021

Por sua vez, vários autores discutem as diferentes visões que já se teve sobre a transferência:

d) A transferência da LM já foi vista de diferentes formas com o passar dos anos (DIAS; MOROSOV, 2013; SALCEDO, 2017; GOMES; CARVALHO, 2013; FRANÇA, 2018; MORAES; LIMA, 2015; DUTRA, 2015; MACHADO, 2019; ANDRADE, 2010).

$\mathrm{Na} \mathrm{AC}$, o conceito de transferência foi trazido do behaviorismo e "referia-se ao processo psicológico pelo qual um conhecimento prévio era transferido e aplicado a uma nova situação de aprendizado" (MORAES; LIMA, 2016, p. 279). De acordo com essa perspectiva, as interferências linguísticas da LM levariam os estudantes de LE a cometerem erros (LADO, 1957 apud SALCEDO, 2017) e, por isso, era importante comparar as diferentes línguas para melhorar o seu ensino. Por outro lado, a AC também acreditava que a transferência poderia ser positiva e facilitar a aprendizagem em casos em que havia elementos similares entre a LM e a LE (GOMES; CARVALHO, 2013; FRANÇA, 2018).

Entretanto, com o tempo, a AC só pôde explicar parte das dificuldades de aprendizagem dos aprendizes (MORAES; LIMA, 2015). O surgimento do conceito de IL proposto por Selinker (1972) impulsiona uma mudança, uma ressignificação da visão que até então se tinha sobre a transferência (MORAES; LIMA, 2015) e, consequentemente, sobre o erro e o aprendiz, o qual passa a ser visto como um ser criativo que testa hipóteses à medida que cria o seu sistema linguístico legítimo (ORTÍZ ALVAREZ, 2002 apud GOMES; CARVALHO, 2013).

Nesse panorama surge, então, a AE, que reconhece a transferência linguística como uma estratégia universal de aprendizagem (ANDRADE, 2010) e como "um fenômeno de caráter cognitivo, que exige comparação e reflexão sobre as línguas" (FERREIRA; DURÃO, 2005, p. 98-99 apud ANDRADE, 2010, p. 53).

Não obstante, não conseguimos encaixar o estudo de Gomes (2017) em nenhuma categoria anterior, pois a autora trabalha com o conceito de transferência de valores paramétricos ligado à Gramática Universal de Chomsky, não abordada por nenhum outro estudo desta revisão.

\section{Considerações finais}

Esta revisão bibliográfica tornou possível a sistematização de estudos dos últimos 10 anos que abordam a transferência linguística na aprendizagem de ELE por brasileiros. Embora o número de trabalhos selecionados não seja expressivo, devido à carência de estudos sobre o tema, há uma variedade quanto aos temas das pesquisas e suas metodologias.

Independentemente da visão que os autores apresentam sobre transferência/interferência linguística, sua presença no processo de ensino e aprendizagem de LE é inquestionável, visto que todos os estudos, apesar dos resultados diferentes, apontam para a existência desse fenômeno. Porém, não há consenso sobre a visão que se tem acerca da transferência linguística, já que alguns autores a vêem como um obstáculo a ser vencido e outros consideram-na necessária no processo de aprendizagem de uma LE.

Tal asserção vai ao encontro do estudo de Villalba (2002), que afirma que a transferência não é um fenômeno totalmente compreendido e a discussão não deve girar em torno de sua existência, mas sim deve-se buscar entender por quais razões o fenômeno ocorre. Por esse motivo, são necessários mais estudos, que possam também contribuir para aprimorar métodos de ensino de ELE.

Portanto, o presente trabalho, longe de ser conclusivo, pretende fornecer subsídios para futuros estudos que tratem sobre a transferência linguística, buscando constantemente entender o papel que a LM tem no ensino e aprendizado de LE.

[...] la "transferencia lingüística" no solo parece inevitable sino que también es imprescindible en el proceso de adquisición de una L2". 
Volume 16 - Número 1 - jan/jul de 2021

\section{Referências}

ANDRADE, O. Necessidades léxicas de universitários brasileiros aprendizes de espanhol: levantamento, descrição e análise. 631 f. 2010. Tese (Doutorado em Letras) - Faculdade de Letras Estrangeiras Modernas, Universidade Estadual de Londrina, Londrina, 2010.

CORDER, S. P. The significance of learner's errors. International Review of Applied Linguistics in Language Teaching, Berlim, v. 5, p. 161-169, 1967.

CORRÊA, C.; ARAUJO, L. Do português ao espanhol: um estudo sobre o uso do perfeito composto por brasileiros aprendizes de E/LE. Revista EntreLínguas, São Paulo, v. 4, n. 1, p. 143-160, 2018.

DIAS, L.; MOROSOV, I. O uso do verbo gustar por aprendizes brasileiros de espanhol como LE. Intersaberes, Curitiba, v. 8, n. 16, p. 96-107, 2013.

DURÃO, A.B.A.B. A fossilização de erros: o estado da questão. Revista Signum: Estudos da Linguagem, Londrina, v. 3, n. 1, p. 41-6, 2000.

DURÃO, A.B.A.B. Transferência (interferência) linguística: um fenômeno ainda vigente? Polifonia, Cuiabá, v. 1, n. 15, p. 67-85, 2008.

DUTRA, E. Os efeitos da instrução com foco na forma na aprendizagem dos clíticos de $3^{\text {a }}$ pessoa do espanhol por universitários brasileiros. 300p. 2015. Tese (Doutorado em Linguística Aplicada) - Faculdade de Letras, Universidade do Vale do Rio dos Sinos, São Leopoldo, 2015.

FERREIRA, R. Similaridades translinguísticas entre português e inglês e os phrasal verbs: a percepção de aprendizes de inglês-LE. 135 f. 2018. Dissertação (Mestrado em Estudos da Linguagem) - Centro de Letras e Comunicação, Universidade Federal de Pelotas, Pelotas, 2018. FERNÁNDEZ LÓPEZ, S. Errores e Interlengua en el Aprendizaje del Español como Lengua Extranjera. Didáctica, Lengua y Literatura, Madri, v. 7, p. 203-215, 1995.

FRANÇA, S. S. Dificuldades na Aprendizagem do Espanhol no Brasil: Reflexões sobre a Escrita. Revista Primeira Escrita, Campo Grande, v. 5, p. 36-45, 2017.

GASS, S.; SELINKER, L. Second Language Acquisition: An Introductory Course. 3. ed. Mahwaw: Lawrence Erlbaum, 774p., 2008.

GOMES, C. Uma análise de interlínguas em aprendizes brasileiros de espanhol: a interferência do infinitivo (flexionado) na escrita de subordinadas finais. 18f. 2017. Trabalho de Conclusão de Curso (Graduação em Letras) - Instituto de Letras, Universidade de Brasilia, Brasília, 2017.

GOMES, M.; CARVALHO, T. A interferência do português/LM no processo de aprendizagem de espanhol/LE: análise e dificuldades de alunos no uso do léxico. In: CARVALHO, T.; BARBOSA, E.; IRIEU, L. (Org). Espanhol na universidade: pesquisa em língua e em literatura. Mossoró: UERN, 2013, p. 79-91.

KELLERMAN, E.; SHARWOOD-SMITH, M. Crosslinguistic influence in second language acquisition. 1. ed. Oxford: Pergamon Press, 206 p., 1986.

MACHADO, P. A influência dos atratores na produção oral de falantes bilíngues português/espanhol e o fator fronteiriço: a transferência em foco. 87 f. 2019. Dissertação (Mestrado em Estudos da Linguagem) - Centro de Letras e Comunicação, Universidade Federal de Pelotas, Pelotas, 2019.

MAGRO, M. C. Análise Contrastiva e Análise de Erros: um estudo comparativo. Cadernos de Linguística e Teoria da Literatura Ensaios de Linguística, Belo Horizonte, v. 3, p. 124-133, 1979.

MORAES, G.; DUTRA, E.; SIMIONI, T. A aprendizagem do presente do subjuntivo do espanhol em orações temporais com cuando por universitários brasileiros: os efeitos da intervenção instrucional na redução de transferência linguística. Trabalhos em Linguística Aplicada, Campinas, v. 57, n. 1, p. 467-491, 2018. 
Volume 16 - Número 1 - jan/jul de 2021

MORAES, G.; LIMA, M. Um estudo qualitativo sobre a transferência na aprendizagem de espanhol por alunos brasileiros. Revista Desenredo, Passo Fundo, v. 11, n. 2, p. 277-293, 2015. MOZZILLO, I. La interlengua: producto del contacto lingüístico en clase de lengua extranjera. Caderno de Letras, Pelotas, v. 11, n.11, p. 65-75, 2005.

OLLER, J.; ZIAHOSSEINY, S. The Contrastive Analysis Hypothesis and Spelling Errors. Language Learning, Detroit, v. 20, n. 2, p. 183-189, 1970.

OTTONELLO, M. La interlengua del hablante no nativo. In: SÁNCHEZ LOBATO, J.; SANTOS GARGALLO, I. (Orgs.). Vademécum para la formación de profesores - Enseñar Español como segunda lengua (L2)/ lengua extranjera (LE). Madrid: SGEL, 2004, p. 369 390.

POZA, J.; MELO, G. A interferência linguística no processo de ensino-aprendizagem de língua espanhola em professores e aprendizes brasileiros. Afluente: Revista de Letras e Linguística, São Luís, v. 3, n. 9, p. 45-61, 2018.

SALCEDO, J. Errores en la transferencia del verbo "ficar" en producciones escritas por aprendices brasileños de E/LE. Revista EntreLínguas, São Paulo, v. 3, n. 1, p. 125-139, 2017. SELINKER, L. Interlanguage. International Review of Applied Linguistics in Language Teaching, Berlim, v. 10, n. 1-4, p. 209-232, 1972.

VILLALBA, T. A transferência na aquisição de Espanhol como L2. In: Marília dos Santos Lima. (Org.). Ensaios (Estudos de Linguagem). Porto Alegre: Sagra Luzzatto, 2002, p. 37 52.

WEINREICH, U. Languages in contact: Findings and Problems. 1. ed. Mouton: The Hague, 149p., 1953. 